\title{
Authentic leadership
}

\section{A proposed framework to support technology acceptance in nursing workplaces}

\author{
Adam Morse
}

The influential role that leaders play in shaping work environments has been widely reported in the nursing literature. ${ }^{1}$ Moreover, researchers have found that nurse leaders have a considerable impact on nurse outcomes (eg job satisfaction and emotional health) ${ }^{1}$ and patient outcomes (eg patient satisfaction and patient safety). ${ }^{2}$ Therefore, ensuring that healthcare organizations have leaders who exhibit positive behaviours is essential, especially during the current era of dynamic technological advancement. The continuous influx and efflux of technology creates change in healthcare processes, and positive leaders are needed to guide staff as they navigate these technological transitions. Various forms of technology play an integral role in combatting a variety of healthcare challenges, including nursing shortages (eg robotic nurses and automatic-scheduling), ${ }^{3}$ geographical barriers to accessing healthcare services (eg telecommunication devices and virtual presence machines), ${ }^{4}$ limited resources (eg devices to reduce electrical consumption), ${ }^{5}$ and environmentally unfriendly practices (eg reusable devices). ${ }^{6}$ Additional technologies that will impact nursing practice are being considered for implementation (eg wearable sensors to measure patient gait ${ }^{7}$ and technology supported nurse training with virtual reality devices). ${ }^{8}$ Such changes will surely require a substantial investment from healthcare leaders and nurses. A synergistic pairing of a positive leadership style and a technology uptake framework may help inform the effective and efficient integration of technology in nursing workplaces. A leadership theory utilized by a number of nursing scholars who study work environments, Authentic leadership theory, which is utilized by a number of nursing scholars who study work environments, ${ }^{9}$ may prove to be a useful framework in facilitating the successful integration of new technologies.

According to authentic leadership theory, when leaders exhibit self-awareness, relational transparency, internalized moral perspective, and balanced processing, their staff experience personal identification with their leader and social identification with their workplace and, in turn, feelings of hope, trust, positive emotions, and optimism. ${ }^{910}$ The embodiment of these feelings by staff members can lead to positive changes in attitudes (eg commitment and engagement) and behaviours (eg job performance and extra effort). ${ }^{9}$ Self-awareness refers to a leader's comprehension of his or her strengths and weaknesses as well as appreciation of how the lives of others are influenced by his or her actions. ${ }^{10}$ Relational transparency encompasses leaders "being open with others, sharing thoughts and feelings and encouraging others to share their ideas, challenges and opinions". ${ }^{11}$ Meanwhile, internalized moral perspective relates to leaders' capacity to make decisions based on personal values and beliefs rather than being impacted by external influences. ${ }^{10}$ Finally, balanced processing involves "leaders who show that they objectively analyze all relevant data before coming to a decision. Such leaders also solicit views that challenge their deeply held positions." ${ }^{10}$ As authentic leaders influence the attitudes and behaviours of staff, ${ }^{9}$ there is an interesting connection with technology implementation.

According to the technology acceptance model (TAM), an individual's attitude is a major variable in determining their behavioural intention to use technology when a new form of technology is introduced into a workplace. ${ }^{12}$ The TAM was developed to address technology users' unwillingness to adopt new technologies, which was seen as a long-standing issue. ${ }^{13}$ TAM focuses on technology users' perceptions of and attitudes toward usefulness ${ }^{14}$ illustrating that the actual uptake of technology is based on users' behavioural intent to use the technology, users' attitude toward employing the technology, and two internal beliefs held by the user: the perceived usefulness of and perceived ease of using a particular technology. Both of these are influenced by a variety of external variables that stem from the environment in which the technology is being introduced. ${ }^{13}$ The work environment is an important factor that positive leaders are able to influence, potentially enhancing the probability of successful technology acceptance and integration.

According to TAM, perceived ease of use relates to users' perception that the use of a system requires less effort compared to other systems. Meanwhile, perceived usefulness refers to users' perceptions of how efficiently a technology improves job performance. ${ }^{13,15}$ As industries are developed on the existence of a positive technology use-performancerelationship, higher usefulness may result in quality performance with anticipated reinforcement from leadership, thus indirectly creating acceptance. ${ }^{15}$ This relates to the influence authentic leadership has on individual perceptions of optimism and self-efficacy. ${ }^{16}$

In the nursing literature, authentic leadership has been linked to a series of consequences for nurses and healthcare organizations, including higher psychological capital (ie feelings of hope, optimism, resiliency, and self-efficacy, ${ }^{16,17}$ as well as increased work engagement. ${ }^{19}$ Some outcomes of authentic leadership show promise for promoting technology acceptance. For instance, authentic leadership has been associated with increased psychological capital among Canadian registered nurses. ${ }^{16}$ It is reasonable to suggest that when registered nurses feel hopeful and resilient, they would be more willing and able to support the introduction of new technologies in the workplace. Similarly, when registered nurses feel more self-efficacious, they may also be more confident when adapting to technological advancement.

Based on this commentary, authentic leaders hold various qualities that may be advantageous to the uptake of new forms 
of technology to advance nursing practice. The TAM illustrates key variables of consideration when implementing new forms of technology into a workplace. Empirically sound research should be conducted to assess the relationship between authentic leadership and technology acceptance. Learning more about how nursing leaders are able to influence technology integration may lead to meaningful policy change that can promote positive outcomes for patients, nurses, and organizations.

\section{REFERENCES}

1. Cummings GG, MacGregor T, Davey M, et al. Leadership styles and outcome patterns for the nursing workforce and work environment: a systematic review. Int J Nurs Stud. 2010 Mar;47(3):363-85. https://doi. org/10.1016/j.ijnurstu.2009.08.006

2. Wong CA, Cummings GG, Ducharme L. The relationship between nursing leadership and patient outcomes: a systematic review update. J Nurs Manag. 2013 Jul;21(5):709-24. https://doi.org/10.1111/ jonm.12116

3. 9th International Conference on Rehabilitation Robotics. ICORR; 2005 Jun 28-Jul 1; Chicago, IL. Piscataway (NJ): IEEE; 2005 Aug. 4658 p. https://doi.org/10.1109/ICORR.2005.1501143

4. Sandelowski M. Visible humans, vanishing bodies, and virtual nursing: complications of life, presence, place, and identity. ANS Adv Nurs Sci. 2002 Mar;24(3):58-70.

5. Franco A, Shaker M, Kalubi D, et al. A review of sustainable energy access and technologies for healthcare facilities in the Global South. Sustainable Energy Technologies and Assessments. 2017 Aug;22:92105. https://doi.org/10.1016/j.seta.2017.02.022

6. Yellowlees PM, Chorba K, Burke Parish M, et al. Telemedicine can make healthcare greener. Telemed J E Health. 2010 Mar;16(2):229-32. https://doi.org/10.1089/tmj.2009.0105

7. Wilson D. An overview of the application of wearable technology to nursing practice. Nurs Forum. 2017 Apr;52(2):124-132. https://doi. org/10.1111/nuf.12177

8. Farra SL, Miller ET, Hodgson E. Virtual reality disaster training: translation to practice. Nurse Educ Pract. 2015 Jan;15(1):53-7. https:// doi.org/10.1016/j.nepr.2013.08.017

9. Avolio BJ, Gardner WL, Walumbwa FO, et al. Unlocking the mask: A look at the process by which authentic leaders impact follower attitudes and behaviors. The Leadership Quarterly. 2004 Dec;15(6):801-23. https://doi.org/10.1016/j.leaqua.2004.09.003

10. Walumbwa FO, Avolio BJ, Gardner WL, et al. Authentic leadership: Development and validation of a theory-based measure. Journal of Management. 2008 Feb;34(1):89-126. https://doi. org $/ 10.1177 / 0149206307308913$

11. Spence Laschinger HK, Wong CA, Grau AL. The influence of authentic leadership on newly graduated nurses' experiences of workplace bullying, burnout and retention outcomes: A cross-sectional study. Int J Nurs Stud. 2012 Oct;49(10):1266-76. https://doi.org/10.1016/j. ijnurstu.2012.05.012

12. Davis FD. A technology acceptance model for empirically testing new end-user information systems: Theory and results [dissertation]. [Cambridge]: Massachusetts Institute of Technology, Sloan School of Management; 1985. $291 \mathrm{p}$.

13. Davis, F. Perceived usefulness, perceived ease of use, and user acceptance of information technology. MIS QUART. 1989 Sep;13(3):319-40. http://doi.org/10.2307/249008
14. Szajna B. Empirical evaluation of the revised technology acceptance model. Manage Sci. 1996 Jan;42(1):85-92. https://doi.org/10.1287/ mnsc. 42.1 .85

15. Bugembe J. Perceived usefulness, perceived ease of use, attitude and actual usage of a new financial management system: a case study of Uganda examinations board. [master's thesis]. [Kampala, Uganda]: Makerere University. 2010 Jun. 71 p.

16. Spence Laschinger HK, Fida R. New nurses burnout and workplace wellbeing: The influence of authentic leadership and psychological capital. Burnout Research. 2014 Jun;1(1):19-28. https://doi. org/10.1016/j.burn.2014.03.002

17. Luthans F, Youssef CM, Avolio BJ. Psychological capital: Developing the human competitive edge. New York: Oxford University Press; 2007. $239 \mathrm{p}$.

18. Bamford M Wong CA, Laschinger $\mathrm{H}$. The influence of authentic leadership and areas of worklife on work engagement of registered nurses. J Nurs Manag. 2013 Apr;21(3):529-40. https://doi.org/10.1111/ j.1365-2834.2012.01399.x 